\title{
Selection of Hyperspectral Narrowbands (HNBs) and Composition of Hyperspectral Twoband Vegetation Indices (HVIs) for Biophysical Characterization and Discrimination of Crop Types Using Field Reflectance and Hyperion/EO-1 Data
}

\author{
Prasad S. Thenkabail, Isabella Mariotto, Murali Krishna Gumma, Elizabeth M. Middleton, David R. Landis, and
} K. Fred Huemmrich

\begin{abstract}
The overarching goal of this study was to establish optimal hyperspectral vegetation indices (HVIs) and hyperspectral narrowbands (HNBs) that best characterize, classify, model, and map the world's main agricultural crops. The primary objectives were: (1) crop biophysical modeling through HNBs and HVIs, (2) accuracy assessment of crop type discrimination using Wilks' Lambda through a discriminant model, and (3) meta-analysis to select optimal HNBs and HVIs for applications related to agriculture. The study was conducted using two Earth Observing One (EO-1) Hyperion scenes and other surface hyperspectral data for the eight leading worldwide crops (wheat, corn, rice, barley, soybeans, pulses, cotton, and alfalfa) that occupy $\sim 70 \%$ of all cropland areas globally. This study integrated data collected from multiple study areas in various agroecosystems of Africa, the Middle East, Central Asia, and India. Data were collected for the eight crop types in six distinct growth stages. These included (a) field spectroradiometer measurements $(350-2500 \mathrm{~nm})$ sampled at $1-\mathrm{nm}$ discrete bandwidths, and (b) field biophysical variables (e.g., biomass, leaf area index) acquired to correspond with spectroradiometer measurements. The eight crops were described and classified using $\sim 20$ HNBs. The accuracy of classifying these 8 crops using HNBs was around $95 \%$, which was $\sim 25 \%$ better than the multi-spectral results possible from Landsat-7's Enhanced Thematic Mapper+ or EO-1's Advanced Land Imager. Further, based on this research and meta-analysis involving over 100 papers, the study established 33 optimal HNBs and an equal number of specific two-band normalized difference HVIs to best model and study specific biophysical and biochemical quantities of major agricultural crops of the world. Redundant bands identified in this study will help overcome the Hughes Phenomenon (or "the curse of high dimensionality")
\end{abstract}

Manuscript received March 12, 2012; revised May 10, 2012, October 02, 2012; accepted March 06, 2013. Date of publication April 23, 2013; date of current version May 13, 2013

P. S. Thenkabail is with the Western Geographic Science Center, U. S. Geological Survey, Flagstaff, AZ 86001 USA (corresponding author, e-mail: pthenkabail@usgs.gov).

I. Mariotto is with the Environmental Science Program, Department of Geological Sciences, University of Texas at El Paso, El Paso, TX 79968 USA.

M. K. Gumma is with the International Rice Research Institute (IRRI), South Asia Breeding Hub, ICRISAT, 502324 Andhra Pradesh, India.

E. M. Middleton is with the Biospheric Sciences Laboratory (Code 618), NASA/Goddard Space Flight Center, Greenbelt, MD 20771 USA.

D. R. Landis is with the Sigma Space Corp., Inc., Lanham, MD 20706 USA.

K. F. Huemmrich is with the University of Maryland Baltimore County, Baltimore, MD 21228 USA.

Color versions of one or more of the figures in this paper are available online at http://ieeexplore.ieee.org.

Digital Object Identifier 10.1109/JSTARS.2013.2252601 in hyperspectral data for a particular application (e.g., biophysical characterization of crops). The findings of this study will make a significant contribution to future hyperspectral missions such as NASA's HyspIRI.

Index Terms-Hyperion, field reflectance, imaging spectroscopy, HyspIRI, biophysical parameters, hyperspectral vegetation indices, hyperspectral narrowbands, broadbands.

\section{INTRODUCTION AND RATIONALE}

$\mathbf{N}$ UMEROUS studies (e.g., [1], [2]) have shown that the Hyperion imaging spectrometer onboard the Earth Observing One (EO-1) satellite has provided significantly enhanced data over conventional multi-spectral remote sensing systems. Hyperspectral narrowbands (HNBs) and hyperspectral vegetation indices (HVIs) derived from EO-1 and field spectral measurements in the 400-2500 nm spectrum allow us to study very specific characteristics of agricultural crops. These include biomass, leaf area index (LAI), pigment content (e.g., chlorophyll, carotenoid, anthocyanin), stress (e.g., due to drought or disease), management properties (e.g., nitrogen application, tillage), and other biochemical properties (e.g., lignin, cellulose, plant residue) [23], [24]. The ability of hyperspectral data to significantly improve the characterization, discrimination, modeling, and mapping of crops and vegetation, when compared with broadband multispectral remote sensing, is well known [8]. This has led to improved and targeted modeling and mapping of specific agricultural characteristics, such as (a) biophysical and biochemical quantities [3]-[8], [13], (b) crop type/species discrimination [9]-[12], [15], (c) stress factors [14], [15], and (d) crop and water productivity, and energy balance [16]-[22]. These benefits will help us better understand a broad range of agricultural applications involving droughts [2], [3], food security [8]-[12], biodiversity [9], [11], and invasive species [9], [24]. Nevertheless, there are still significant knowledge gaps that require further research.

Contiguous bands of spectrometer data allow for accurate retrieval of plant biophysical and biochemical quantities using methods like continuum removal, first discussed by Clark and Roush in 1984 [25]-[28]. However, since information about agriculture is time sensitive, approximate analyses, quickly 


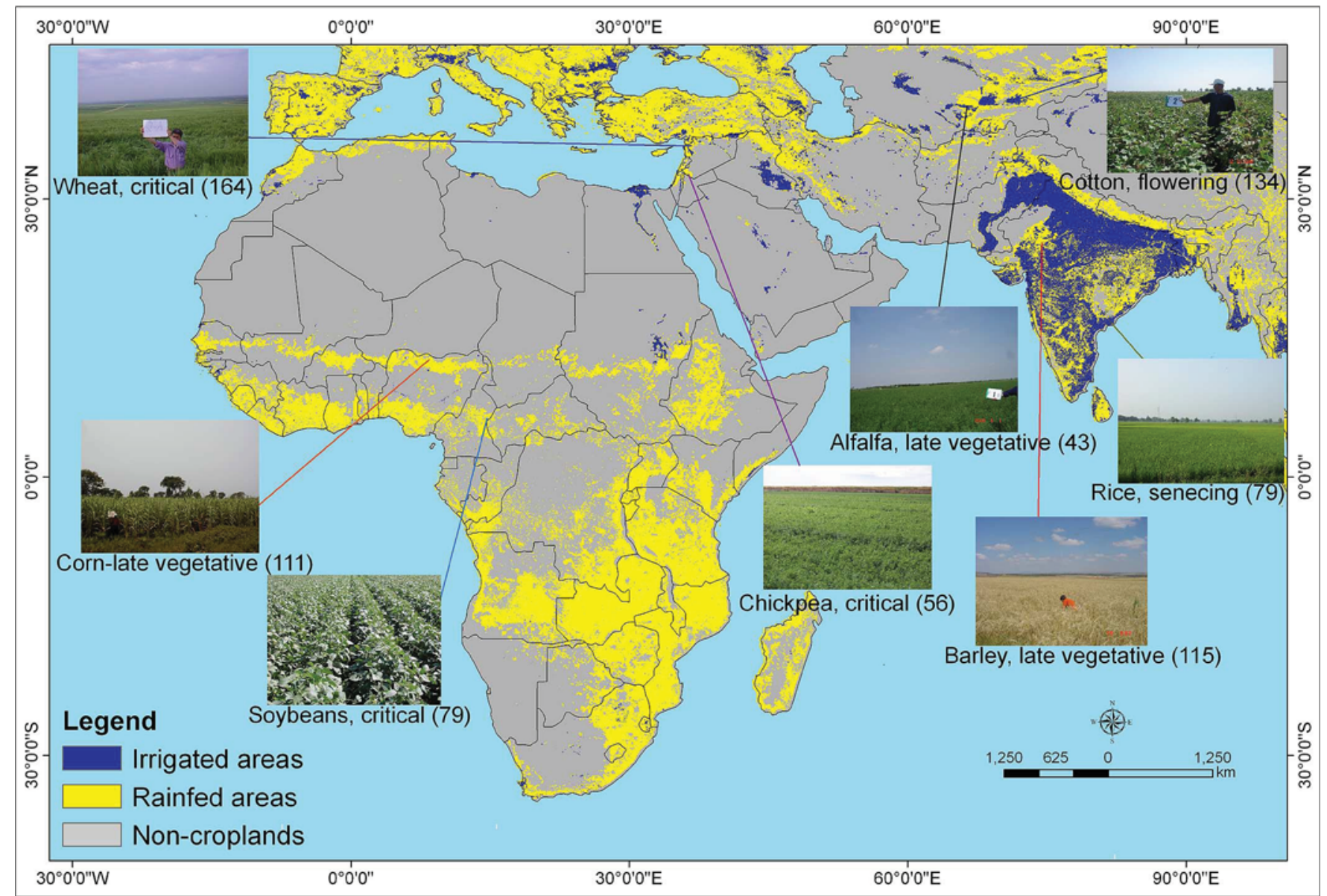

Fig. 1. Study areas from where hyperspectral data from spectroradiometer and Hyperion were gathered. The irrigated and rainfed cropland study areas of eight major world crops (Table I) in distinct agroecosystems for which hyperspectral data from spectroradiometer and Hyperion were collected from four study areas (see details in Table II).

obtained using one or more HVIs may be more useful than slow detailed retrievals based on continuum removal or similar approaches. Thus, there is an important need to develop hyperspectral narrowband indices. Recent research has demonstrated that the optimal information required to quantify, discriminate, and classify crop characteristics may be captured with a relatively small number of specific narrowbands [8], [23], [29]. However, these studies were limited to small areas, lacking regional or global perspective, and they contain significant uncertainties.

Large data volumes can be reduced through several data mining methods such as [8], [23], [30], [31], [34], [35]: (1) feature selection (e.g., principal component analysis, derivative analysis); (2) $\lambda$ versus $\lambda \mathrm{R}^{2}$ - plots between the different wavelength bands; (3) partial least squares (PLS), (4) stepwise linear regressions; and (5) hyperspectral vegetation indices (HVIs). These data mining methods led to: (a) reduction in data dimensionality, (b) reduction in data redundancy, and (c) extraction of unique information. There are several other methods of analyzing hyperspectral data such as Hierarchical Multiple Endmember Spectral Mixture Analysis (MESMA) [7], continuum removal [37], derivative vegetation indices [31], unmixing approaches [10], neural networks [30], and others [8].

In this current research, we made use of hyperspectral data from two Hyperion images and in-situ spectroradiometer data
TABLE I

AREA OF THE EIGHT LEADING WORLD CROPS

\begin{tabular}{lll}
\hline \multicolumn{1}{c}{ Crop } & $\begin{array}{c}\text { World } \\
\text { Area (ha) }\end{array}$ & $\begin{array}{c}\text { World } \\
\text { \% }\end{array}$ \\
\hline Wheat & $402,800,000$ & 22.5 \\
Maize & $227,100,000$ & 12.7 \\
Rice & $195,600,000$ & 10.9 \\
Barley & $158,000,000$ & 8.8 \\
Soybeans & $92,700,000$ & 5.2 \\
Pulses & $79,400,000$ & 4.4 \\
Cotton & $53,400,000$ & 3.0 \\
Alfalfa & $30,000,000$ & 1.7 \\
\hline Total of major 8 crops & $\mathbf{1 , 2 3 9 , 0 0 0 , 0 0 0}$ & 69.1 \\
(ha) & $553,000,000$ & 30.9 \\
\hline Others (ha) & $1,792,000,000$ & 100.0 \\
Total cropland (ha) & & \\
\hline
\end{tabular}

Derived from Monfreda et al. [41] who aggregated the major crops of the world by combining national, state, and county level census statistics with their global croplands database ( $\sim 10 \mathrm{~km}$ by $10 \mathrm{~km})$ latitude-longitude grid. These datasets depict circa the year 2000 the area (harvested) [41].

(1153 samples) of eight major worldwide crops (wheat, corn, rice, barley, soybeans, pulses, cotton, alfalfa; Table I). These crops occupy $\sim 70 \%$ of all cropland areas of the world (Table I). These data were collected from distinct agroecosystems in Africa, the Middle East, Central Asia, and India (Fig. 1) and 
represent eight distinct plant growth stages, each with sufficiently large sample size. These data were then used in the development of robust models of crop productivity $\left(\mathrm{CP} ; \mathrm{kg} / \mathrm{m}^{2}\right)$ using HNBs and HVIs.

As the number of bands in an image increases, the number of observations required to train a classifier increases exponentially to maintain classification accuracy [1], [2], [30]. When the spectral dimensionality of the data increases, this causes a loss of classifiability for an image with the same fixed number of training samples [1], [2], [30]. This is called the Hughes Phenomenon (or "the curse of high dimensionality") [38]. We examined the high dimensionality problem for crop classification issues for biophysical retrievals. We used unique data mining techniques involving several thousand HVIs for each investigated crop variable, with the goal of identifying and eliminating redundant spectral bands.

Our main objectives were to: (1) select the best Hyperion narrowbands to compose two-band HVIs (i.e., normalized differences) for biophysical characterization of biomass, LAI, plant height, plant density, and grain yield; (2) identify the best HNBs and indices (HVIs) from field reflectance spectra for discriminating crop types and for comparing their performance with the corresponding broadband indices; and (3) perform meta-analysis to select optimal HNBs and HVIs for agriculture monitoring.

\section{Methodology}

\section{A. Study Areas}

Four distinct study areas (Fig. 1) were selected based on the available hyperspectral and corresponding biological data (Table II) for the eight major world crops in various agroecological zones. These data were collected during different years (2000 through 2010) [8], [23], [32]-[35]. The study areas (Fig. 1) were: (A) Syria, semi-arid with supplemental irrigation (barley, pulses, soybeans); (B) Uzbekistan, heavily irrigated croplands (wheat, cotton, rice, alfalfa); (C) Africa, agricultural crops from different agroecological and climate zones (e.g., savanna in Sudan, Northern Guinea, Southern Guinea, with crops of corn, soybeans, and rice); and (D) India, rainfed croplands in semi-arid environments (barley, pulses, soybeans). Detailed characteristics of these data gathering efforts are described in various places [8], [23], [32]-[35] and will not be restated here. Data analysis of pooled, cross-site hyperspectral data for leading global crops from distinct agroecosystems of the world is quite rare, making this study unique.

\section{B. Field Spectroradiometer Data}

All field spectral measurements were made using Analytical Spectral Devices Fieldspec instruments (ASD, Boulder, CO, USA), which gather data between 350-2500 nm [8]. For the eight crops (Figs. 1, 2), there were a total of 1553 data points (Table II) for which hyperspectral data were available from various ASD Fieldspec instruments. These data were available for 6 distinct plant growth stages: early vegetative, mid vegetative, flowering, tillering, critical, and senescing. "Critical" growth stages vary for each crop. For rice crops, "critical" growth stages are tiller initiation, flowering, and milky stage.
For wheat crops, "critical" growth stages are crown initiation, flowering, joining, milky, and tillering. Gathering these spectra involved optimizing the integration time (typically set at 17 $\mathrm{ms}$ ), providing fore-optic information, recording dark current, and collecting white reference reflectance. At each site, 10 reflectance measurements were consistently taken along a transect, using a ladder to obtain a $3 \mathrm{~m}$ high nadir view. Crop variables collected during field visits included: (1) crop type (Table I); (2) crop growth stages (Fig. 2); (3) biophysical quantities such as wet and dry biomass $\left(\mathrm{kg} / \mathrm{m}^{2}\right)$, leaf area index $\left(\mathrm{m}^{2} / \mathrm{m}^{2}\right)$, plant height $(\mathrm{mm})$, and canopy cover $(\%)$; and $(4)$ biochemical variables such as leaf nitrogen and plant pigments. Details of the methods and approaches of collecting data are discussed elsewhere [31], [33]-[35].

\section{EO-1 Hyperion Data}

Two Hyperion images were available for the Uzbekistan study area, taken within 2 days of the corresponding field data (Fig. 3). Hyperion Level 1 products are radiance values stored as 16-bit signed integers. These were converted from radiances ( $\mathrm{W} \mathrm{m}^{-2} \mathrm{sr}^{-1} \mu \mathrm{m}^{-1}$ ) to at-sensor reflectance. Several different atmospheric corrections were tried, but all had problems providing good correction values. Thus, using the original at-sensor reflectance data was considered the best option.

The first atmospheric correction tried was the MODTRAN-based FLAASH (Fast Line-of-sight Atmospheric Analysis of Spectral Hypercubes) routine, which retrieves aerosol and water vapor information from the image to provide well-adjusted input for the atmospheric correction [28]. However, using FLAASH on the two Hyperion images resulted in over-correction and/or uncertainties. These poor results may have been obtained because of the linearity assumption, which presumes uniform atmospheric transmission, scattering, and adjacency effects throughout the scene [36]. Also, very accurate water vapor and aerosol retrievals are only possible when the image contains bands in exact wavelength positions. In addition, FLAASH does not accept any kind of ancillary data, such as ozone, surface pressure, or water vapor for cases when this cannot be retrieved from the image data itself. In our study, a few pixels in the Hyperion images with specular reflectance seemed to influence the surface reflectance correction and there was uncertainty in the aerosol and water vapor retrievals due to the small area coverage of the Hyperion images. Essentially, FLAASH was unable to adjust for variations in several atmospheric parameters (e.g., ozone, surface pressure, and water vapor) [28], limiting the usability of FLAASH-derived surface reflectance for our study.

We also attempted to provide a simple alternative atmospheric correction [34] using the improved dark object subtraction technique [39], [40] to derive surface reflectance from apparent or at-sensor reflectance. This alternative correction appeared to retain features involving either oxygen, water vapor, or carbon dioxide, and thus produced poor results as well.

Original Hyperion images have 242 bands each of $10 \mathrm{~nm}$ bandwidth between 400 and $2500 \mathrm{~nm}$, but only 157 narrowbands were used. These useful bands were visible and nearinfrared (VNIR) bands 8-57 (427.55-925.85 nm), and SWIR 
TABLE II

Study Areas, Crops Studied, and Hyperspectral Data Points. A Total of 1553 Hyperspectral Data Points Were Collected for Eight Major World Crops (Figs. 1, 2; TABLE I) USING GRound BASED SPECTRORADIOMETER

\begin{tabular}{|c|c|c|c|c|c|}
\hline $\begin{array}{l}\text { Study } \\
\text { area } \\
\text { (\#) }\end{array}$ & $\begin{array}{l}\text { Study } \\
\text { Areas } \\
\text { Latitude and } \\
\text { longitude } \\
\text { (name) }\end{array}$ & $\begin{array}{l}\text { Major crops } \\
\text { Studied } \\
\text { (crop types) }\end{array}$ & $\begin{array}{l}\text { Major crop } \\
\text { characteristics } \\
\text { for which data gathered } \\
\text { (crop parameters) }\end{array}$ & $\begin{array}{l}\text { Hyperspectral } \\
\text { data and } \\
\text { Data acquisition } \\
\text { dates } \\
\text { (sensor types; } \\
\text { dates) }\end{array}$ & $\begin{array}{l}\text { number } \\
\text { of } \\
\text { data } \\
\text { points } \\
\text { (\#) }\end{array}$ \\
\hline 1 & $\begin{array}{l}\text { Africa } \\
\text { (Sudan savanna, } \\
\text { N. guinea } \\
\text { savanna, } \\
\text { S. guinea savanna, } \\
\text { derived savanna, } \\
\text { humid forests) } \\
\text { Latitude: } 7 \text { to } 12 \\
\text { degrees North } \\
\text { Longitude: } 1 \text { to } 8 \\
\text { degree East }\end{array}$ & $\begin{array}{l}\text { corn, soybeans } \\
\text { rice }\end{array}$ & $\begin{array}{l}\text { biomass } \\
\text { plant height, plant density, } \\
\text { crop types }\end{array}$ & $\begin{array}{l}\text { Spectroradiometer; } \\
\text { March- April, } \\
2002\end{array}$ & 532 \\
\hline 2 & $\begin{array}{l}\text { Syria } \\
\text { (supplemental } \\
\text { irrigated areas) } \\
\text { Latitude: } 35.56 \text { to } \\
36.5 \text { degrees } \\
\text { North } \\
\text { Longitude: } 36.50 \\
\text { to } 37.43 \text { degree } \\
\text { East }\end{array}$ & $\begin{array}{l}\text { Barley, corn, } \\
\text { soybeans, wheat, } \\
\text { pulses (chickpea) }\end{array}$ & $\begin{array}{l}\text { biomass, LAI, Yield, } \\
\text { plant height, plant density, } \\
\text { nitrogen, crop types }\end{array}$ & $\begin{array}{l}\text { spectroradiometer, } \\
\text { August- } \\
\text { September, 1997, } \\
\text { April-May, } 1998\end{array}$ & 467 \\
\hline 3 & $\begin{array}{l}\text { Uzbekistan } \\
\text { (irrigated areas) }\end{array}$ & $\begin{array}{l}\text { wheat, rice, cotton, } \\
\text { alfalfa, corn }\end{array}$ & $\begin{array}{l}\text { biomass, Yield, } \\
\text { plant height, plant density, }\end{array}$ & $\begin{array}{l}\text { Hyperion } \\
08 / 01 / 2007 \\
08 / 06 / 2007 \\
\text { spectroradiometer }\end{array}$ & 372 \\
\hline & $\begin{array}{l}\text { Latitude: } 40.38 \\
\text { degrees North } \\
\text { Longitude: } 71.78 \\
\text { degree East }\end{array}$ & & crop types & $\begin{array}{l}\text { July-September, } \\
2006 \text { and } 2007\end{array}$ & \\
\hline & India & barley, soybeans, & biomass & Spectroradiometer & 182 \\
\hline 4 & (rainfed areas) & pulses (chickpea) & plant height, plant density, & $\begin{array}{l}\text { July-September, } \\
2009\end{array}$ & \\
\hline & $\begin{array}{l}\text { Latitude: } 26.0 \text { to } \\
26.9 \text { degrees } \\
\text { North } \\
\text { Longitude: } 72.10 \\
\text { to } 72.9 \text { degree } \\
\text { East }\end{array}$ & & crop types & & \\
\hline
\end{tabular}

bands 79-224 (932.72-2395.53 nm). The uncalibrated bands (357-417 nm, 936-1068 nm, and 852-923 nm) were dropped as were wavebands in atmospheric windows $(1306-1437 \mathrm{~nm}$, 1790-1992 nm, and 2365-2396 nm) which had high noise. The 

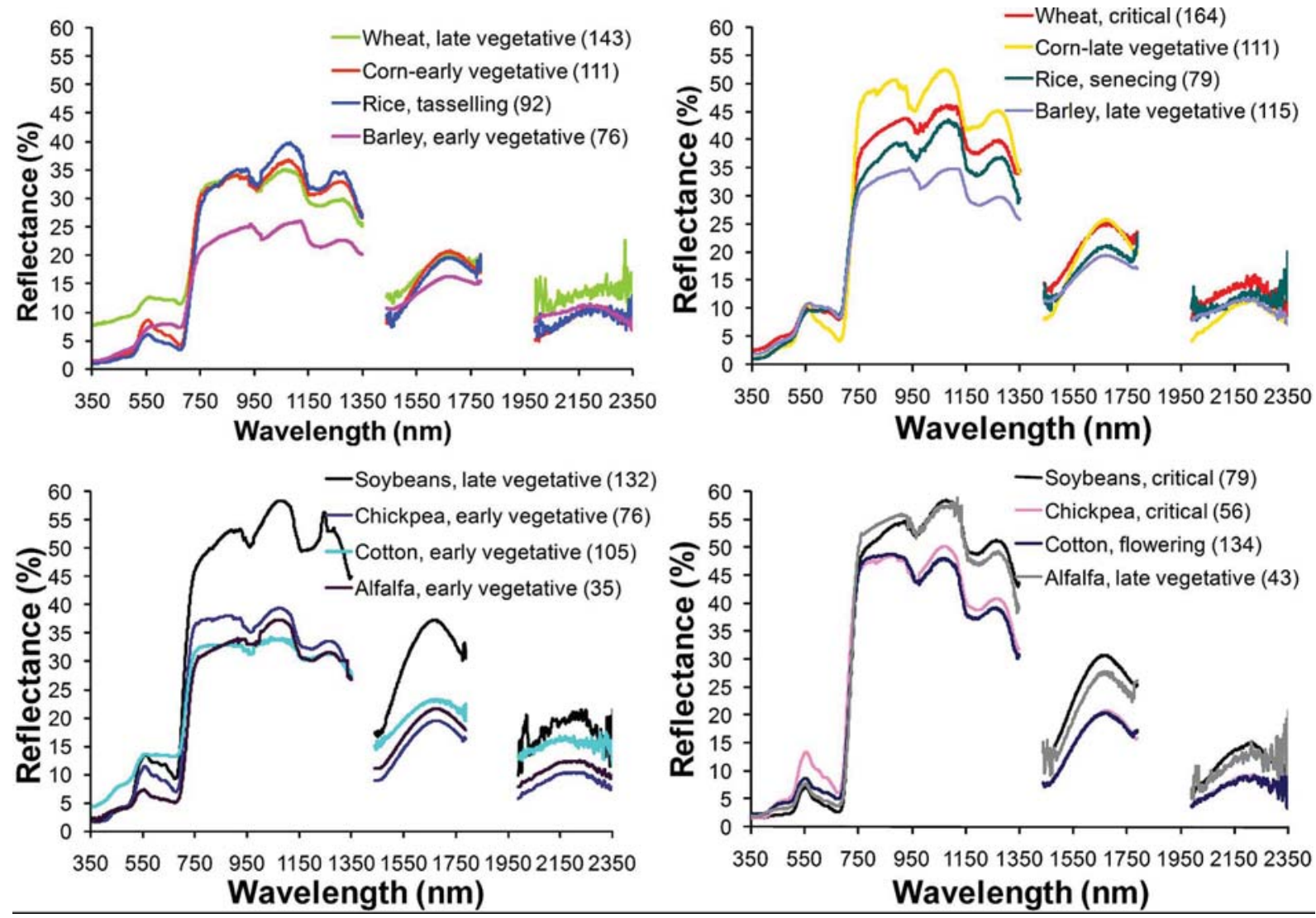

Fig. 2. Cross-site hyperspectral spectroradiometer data. Cross-site mean (regardless of which study site (1-4, Table II)) spectral plots of eight leading world crops in various growth stages. (A) Four crops at different growth stages; (B) same four crops as in A but in different growth stages; (C) four more crops at early growth stages; and (D) same four crops as C, but at different growth stages. Note: numbers in bracket are sample sizes.

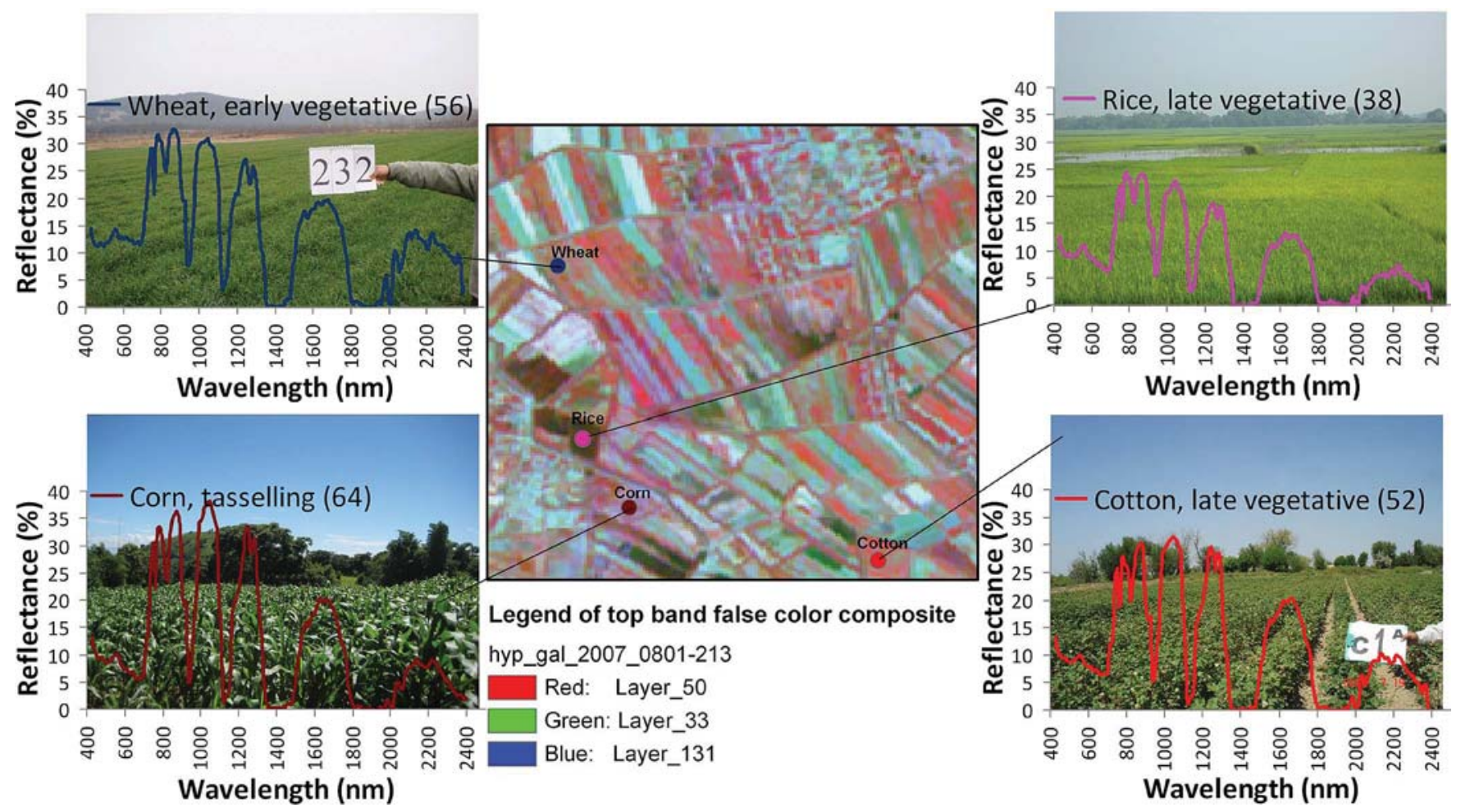

Fig. 3. Hyperion data of crops illustrated for typical growth stages in the Uzbekistan study area. The Hyperion data cube shown here is from a small portion of one of the two Hyperion images. The Hyperion spectra of crops are gathered from different farm fields in the two images and their average spectra illustrated here along with the sample sizes indicated within the bracket. The field data was collected within two days of the image acquisition. 


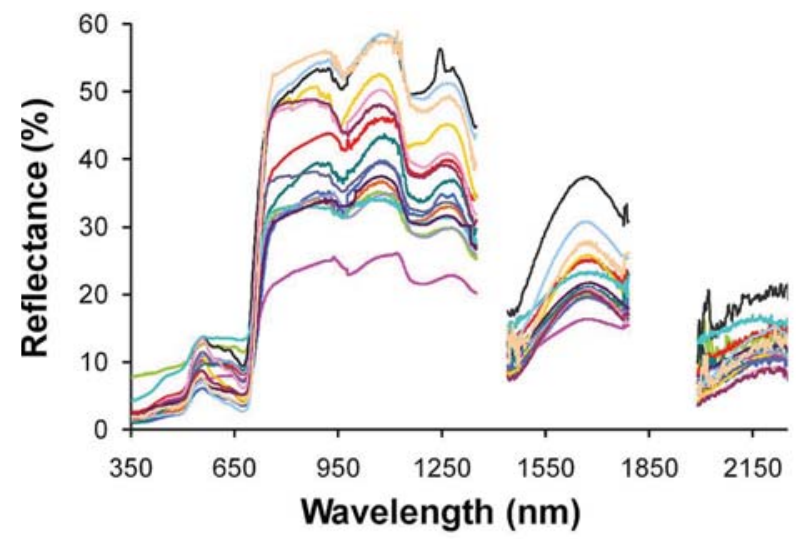

-Wheat, late vegetative (143)

- Rice, tasselling (92)

-Wheat, critical (164)

- Rice, senecing (79)

- Soybeans, late vegetative (132)

- Cotton, early vegetative (105)

- Soybeans, critical (79)

- Cotton, flowering vegetative (134)

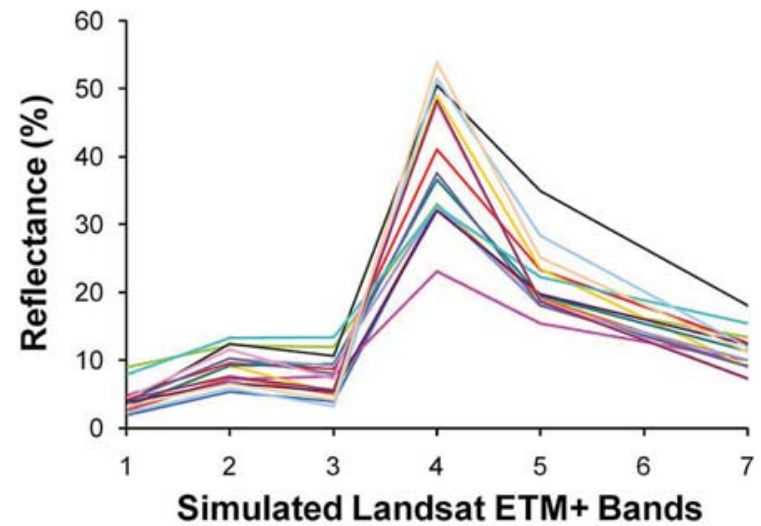

- Corn-early vegetative (111)

- Barley, early vegetative (76)

- Corn-late vegetative (111)

- Barley, late vegetative (115)

- Chickpea, early Vegetative (76)

—Alfalfa, early vegetative (35)

- Chickpea, critical (56)

Alfalfa, late vegetative (43)

Fig. 4. Original narrowband versus simulated broadband reflectance field spectra of leading world crops. The hyperspectral reflectance field spectra of eight leading crops, each at two distinct growth stages, are shown for narrowbands (left) and simulated for Landsat ETM+ broadbands (right). Note: sample size within brackets.

at-sensor reflectances were then obtained for the wheat (56 samples), corn (64), rice (38), cotton (52), and alfalfa (32) crops from the two Uzbekistan images. These images were acquired during the crop stages shown in Fig. 3. The study addressed the early growth stage for wheat, and late growth stages for the other four crops (corn, rice, cotton, and alfalfa). The crops in other growth stages within these images were ignored since the sample sizes were inadequate $(<20$ pixels). The average at-sensor reflectance spectra of the 5 crops at either early or late growth stages are shown in Fig. 3.

\section{Methods for Objective 1: Selection of Hyperion}

Narrowbands to Compose Two-Band Indices for Biophysical Characterization

Contour plots of R-square values for wavelength bands and HVIs with rigorous search criterion are considered the best choice for the comprehensive assessment of hundreds of wavebands and thousands of indices [31], [34], [35], [42]. Two-band normalized difference Hyperion indices (HVIs) were examined for biophysical characterization. These indices were computed from every possible 2-band combination of Hyperion bands from the two images of Uzbekistan. The HVIs were computed using the standard equation [31]:

$$
\text { narrow-waveband }\left(\mathrm{HVI}_{i j}\right)=\frac{R_{j}-R_{i}}{R_{j}+R_{i}}
$$

where, $i, j$ are the two waveband centers for reflectance (R, \%) for 157 narrow-wavebands. For each variable (e.g., biomass) per crop, there are 12246 unique indices possible. These were calculated as $(((157 * 157)-157) / 2)$; divided by 2 because the values above and below the diagonal are the transpose of one another, and minus 157 because these are diagonal values. Each of these HVIs were then correlated with crop variables, such as wet and dry biomass $\left(\mathrm{kg} / \mathrm{m}^{2}\right)$, leaf area index $\left(\mathrm{m}^{2} / \mathrm{m}^{2}\right)$, and plant height (mm).

\section{E. Methods for Objective 2: Selection of FieldSpec and Two-Band Narrowband Indices for Discriminating Crop Types}

We adopted a discriminant model [35], [43] to determine how well the eight crops were distinguished based on hyperspectral narrowband data (Fig. 4(a)) and simulated corresponding broadband data (e.g., for Landsat ETM+, Fig. 4(b)). Crop discrimination was performed using Wilks' Lambda, a stepwise discriminant analysis (SDA) [43], because it provided the most lucid, rapid, and straightforward results to determine the seperability among multiple classes [35]. In addition to the Wilks' Lambda, there are a number of other SDA methods for crop class separability, such as [31], [34], [35]: (a) Jefferies-Matusita (JM) index; (b) Pillai trace; and (c) canonical correlation. Wilks' Lambda is the most commonly used and reported, however Pillai's criterion is useful for small or unequal sample sizes.

The Wilks' Lambda SDA (PROC STEPDISC [43]) begins with no waveband information in the model. At each step, the variable (e.g., specific narrowband) that contributes most to the discriminatory power of the model is entered. The stepwise process continues, with the inclusion of variables that meet the criterion to stay, and stops when no additional variables add to model success [43]. The class separability of the 1553 hyperspectral measurements representing various growth stages of the eight leading world crops was determined using Wilks' 
Lambda [34]. The discriminant model is akin to an error matrix [444], providing overall accuracies and errors of omissions and commissions. The original high-resolution field spectra were aggregated to $10 \mathrm{~nm}$ bandwidths (akin to Hyperion and HyspIRI bands) in the ranges of 390-1350 nm, 1440-1790 nm, and 1990-2360 nm. This resulted in 160 aggregated HNBs, which were then aggregated again to simulate the Landsat ETM+ six non-thermal bands and EO-1 ALI's nine bands (e.g., Fig. 4).

\section{F. Methods for Objective 3: Meta-Analysis to Select Optimal HNBS and HVIS}

To overcome the parochial results from small local studies, this research adopted a regional perspective by integrating data from numerous agricultural crops grown in distinct agroecosystems with robust models developed using numerous biophysical characteristics. Meta-analysis used data gleaned from over 100 research papers [8] to derive optimal HNBs and HVIs based on spectroradiometers with a consistent set of measurements. These HNBs and HVIs help explain more of the variability of vegetation biophysical and biochemical characteristics [7], [8] and they are targeted indices to study specific biophysical and biochemical quantities [10]. These include chlorophyll indices based on correlation success, such as leaf chlorophyll index (LCI), red-edge vegetation stress index (RVSI), and derivative chlorophyll index (DCI) (see Table IV for description of indices). In addition, several HVI formulations are based on physiological criteria, such as photochemical reflectance index (PRI), normalized difference water index (NDWI), and anthocyanin reflectance index (ARI) (see Table IV for description of indices).

\section{RESULTS AND DISCUSSION}

\section{A. Selection of Hyperion Narrowbands to Compose Two-Band Indices for Biophysical Characterization}

We used the Uzbekistan Hyperion images (Section II.C, Fig. 3) to examine the HVI relationships to crop biomass for wheat and corn crops. These two crops were chosen because they had the largest sample sizes and are the two leading crops of the world (Table I). Fig. 5 shows contour plots of coefficients of determination (R-square) for all pairs of wavelength bands in two band normalized difference HVI with: (a) wheat wet biomass (Fig. 5, above the diagonal), and (b) corn crop wet biomass (Fig. 5, below the diagonal). The "bull's eye" regions (Fig. 5, colored areas) are areas of highest $\mathrm{R}^{2}$ - values and are used to determine the most important HNBs. The large number of wavebands in the gray areas have the lowest $\mathrm{R}^{2}$-values $(<0.5)$ and hence are considered to be redundant. These wavelength plots are a powerful means of determining the most useful Hyperion narrowbands. Based on these plots and meta-analysis (Section III.C), we selected those HNBs having high $\mathrm{R}^{2}$-values (Table IV), in agreement with several studies (e.g., [8], [23], [31], [34], [35]).

The waveband combinations that provide the best $\mathrm{R}^{2}$-values between HVIs and biophysical quantities are different for wheat and corn crops (Fig. 5). This is due to different growing conditions (e.g., soils, climate, management practices) and different

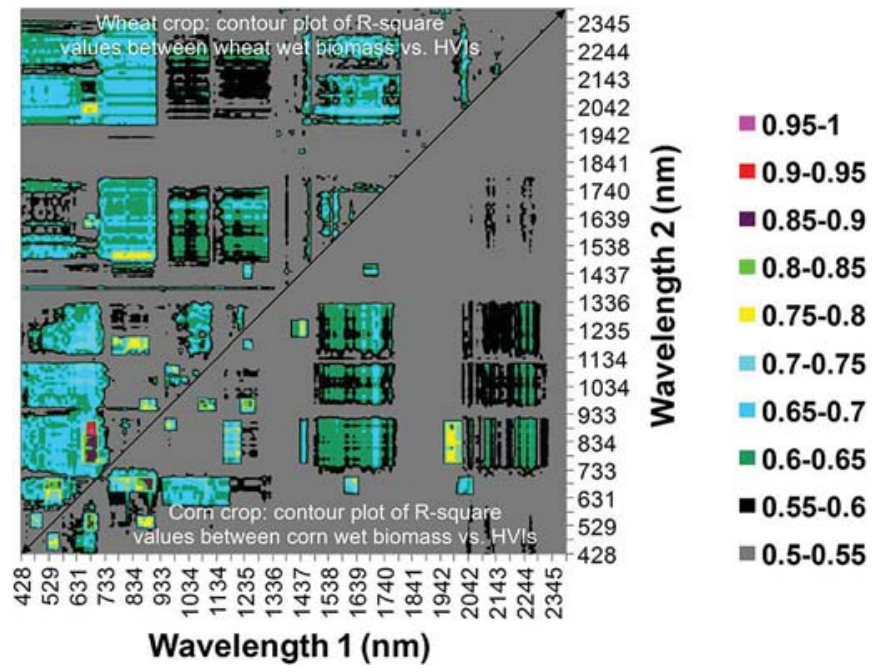

Fig. 5. Contour plot of $\lambda$ versus $\lambda \mathrm{R}^{2}$ - values for wavelength bands between two-band hyperspectral vegetation indices (HVIs) and wet biomass of wheat crop (above diagonal) and corn crop (below diagonal). The 242 Hyperion bands were reduced to 157 bands after eliminating uncalibrated bands and the bands in atmospheric window. HVIs were then computed using the 157 bands leading to 12246 unique two-band normalized difference HVIs each of which were then related to biomass to obtain R-square values. These $\mathrm{R}^{2}$-values were then plotted in a $\lambda$ versus $\lambda \mathrm{R}^{2}$-contour plot as shown above.

agroecosystems. This is why major crops from distinct agroecosystems have been pooled and studied together.

\section{B. Selection of FieldSpec Narrowbands for Crop Discrimination}

The Wilks' Lambda [34], [35] was used to see how well the eight crops were separated using various number of HNBs vs. Landsat ETM+ bands and EO-1 ALI bands (Fig. 6). It was found that the smaller the value of the Wilks' Lambda statistic, the greater the separability. So, for perfect separation of the eight crops, we would need a Wilks' Lambda of zero. Since hyperspectral sensors have hundreds of wavebands, the likelihood of finding ones that can separate vegetation/crop types or biochemical quantities increases drastically. At about 20 bands, Wilks' Lambda becomes near zero (Fig. 6) indicating near perfect separability of the eight crops. In comparison, the Wilks' Lambda of the eight crops simulated for the Landsat ETM+ and the ALI bands were only about 0.49 and 0.32 respectively, indicating poor differentiation of crop types using these broadbands.

The discriminant model (Section II.E, 1) was used to determine overall accuracies in classifying the eight crops using the HNBs and BBs (Fig. 7). About 20 HNBs provided a classification accuracy of $95 \%$ (Fig. 7). Additional bands increased that by an insignificant amount, leading to near asymptotic accuracy beyond 20 bands. In comparison the maximum accuracies attained were $67 \%$ for the six non-thermal simulated Landsat $E T M+$ bands, and $71 \%$ for the nine simulated ALI bands. The best band combinations of HNBs for separating or discriminating crop types or classifying them are shown in Table III.

If the number of bands remains high, the number of observations required to train a classifier increases exponentially to maintain classification accuracies [30], due to the Hughes Phenomenon. For example, three narrowbands centered at $540 \mathrm{~nm}$, 


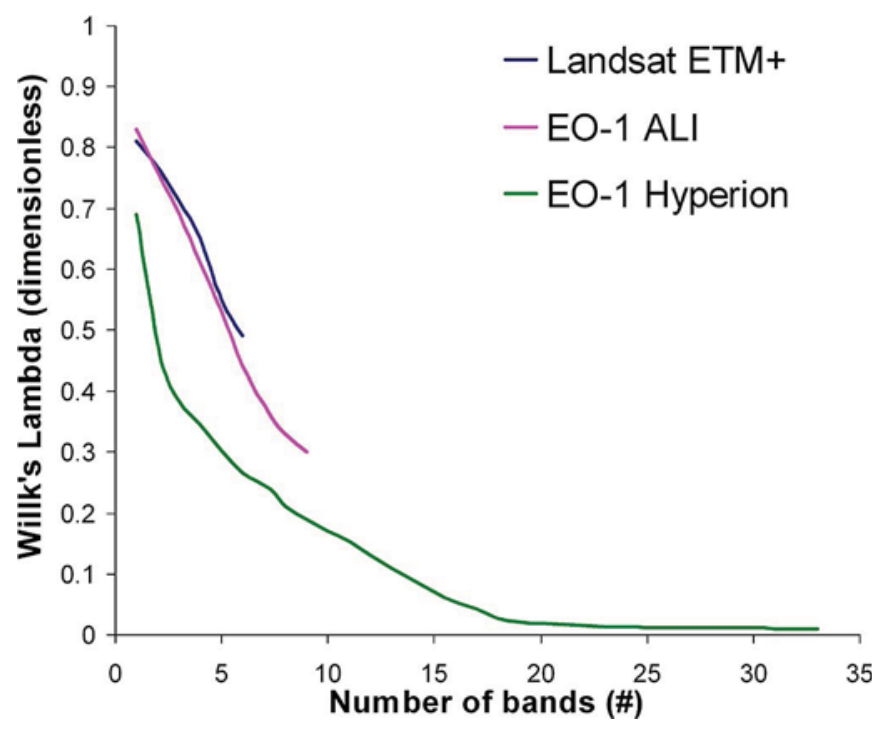

Fig. 6. Separating eight major crops of the world based on Wilks' Lambda stepwise discriminant analysis (SDA) method using: (a) broadband data of Landsat ETM+ and EO-1 ALI, and (b) hyperspectral narrowband (HNB) data of EO-1 Hyperion using some of the data of three study areas. Note: the smaller the Wilks' Lambda the greater the separability. A Wilks' Lambda of 1 means perfect separability. It took about $25 \mathrm{HNBs}$ to achieve near perfect separability between eight crops.

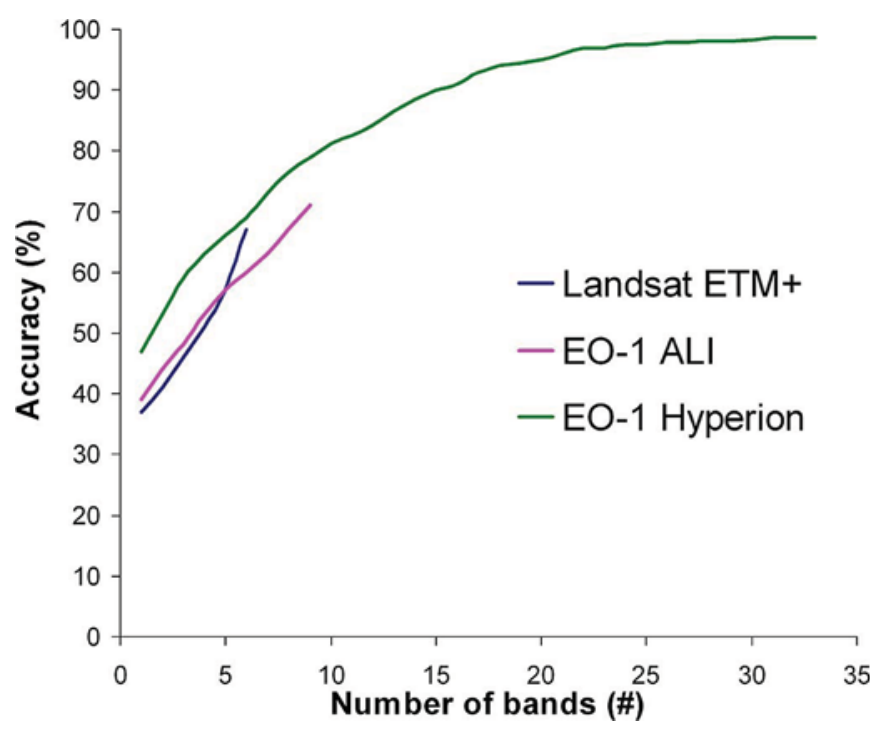

Fig. 7. Crop classification performance of hyperspectral narrowbands (HNBs) versus multispectral broadbands (MBBs). Overall accuracies in classifying five agricultural crops using simulated reflectance field spectra of Landsat ETM+ and EO-1 ALI broadband Landsat broadbands vs. Hyperion hyperspectral narrowbands. Overall accuracies attained using six non-thermal Landsat bands was about $60 \%$ whereas about 20 hyperspectral narrow bands provided about $90 \%$ overall accuracy. Beyond 20 bands, any increase in accuracy with increase in additional bands is very minor.

$550 \mathrm{~nm}$, and $560 \mathrm{~nm}$ are almost perfectly correlated to one another when studying agricultural crop biophysical characteristics. Therefore, wavebands that provide the best information should be selected and the others dropped when studying crops. Nevertheless, the bands deemed redundant for one application may be valuable in other applications, such as in the study of geology, water/ice, and marine resources.
TABLE III

The Best 4, 6, 10, 15, AND 20 BAND COMBINATIONS OF HYPERSPECTRAL NARROWBANDS (HNBS) FOR SEPARATING OR DISCRIMINATING CROP TYPES OR Classifying THEM

\begin{tabular}{|l|l|}
\hline Best 4 bands & $550,687,855,1180 \mathrm{~nm}$ \\
\hline Best 6 bands & $550,687,855,1180,1650,2205 \mathrm{~nm}$ \\
\hline Best 10 bands & $\begin{array}{l}550,687,720,855,970,1180,1245,1450,1650, \\
2205 \mathrm{~nm}\end{array}$ \\
\hline Best 15 bands & $\begin{array}{l}515,550,650,687,720,760,855,970,1110,1180, \\
1245,1450,1650,1950,2205 \mathrm{~nm}\end{array}$ \\
\hline Best 20 bands & $\begin{array}{l}490,515,531,550,570,650,687,720,760,855, \\
970,1045,1110,1180,1245,1450,1650,1760, \\
\end{array}$ \\
& $1950,2205 \mathrm{~nm}$ \\
\hline
\end{tabular}

\section{Selection of Optimal HNBs and HVIs for Crop Biochemical Characteristics}

Selection of HNBs and HVIs (Table IV) for crop biochemical characteristics required rigorous meta-analysis (Section II.F). The relevance of these HNBs and their use in calculating HVIs has been established by numerous researchers (Table IV) and is discussed in various chapters of Thenkabail et al. [8]. For example, Thenkabail et al. [8] shows that a waveband centered at $550 \mathrm{~nm}$ provides excellent sensitivity to plant nitrogen, one centered at $515 \mathrm{~nm}$ is best for pigments (carotenoids, anthocyanins), and one at 970 or $1245 \mathrm{~nm}$ is preferred to study plant moisture fluctuations. Lignin, cellulose, protein, and nitrogen have relatively low reflectance and strong absorption in SWIR bands due to water absorption that masks other absorption features [4], [5]. Thus, there is sufficient scope to expand this research further to find additional hyperspectral two-band vegetation indices (HTBVIs) (Table IV) and hyperspectral multiband vegetation indices (HMBVIs) [31], [33]-[35]. This could lead to identifying specific biophysical indices such as biomass, LAI, plant height, canopy cover, fraction of absorbed photosynthetically active radiation (fAPAR), net primary productivity (NPP), and grain yield. Discrimination of subtle biochemical constituents such as the starches, proteins, lignin, and cellulose requires fine (3 to $5 \mathrm{~nm}$ ) spectral bandwidths (Fig. 8) [8]. Biochemical factors such as chlorophylls a and b, total chlorophyll, carotenoids, anthocyanins, nitrogen, water, and those involved in plant structure (e.g., lignin, cellulose) (Fig. 8) require similar bandwidths.

NASA's planned hyperspectral satellite, HyspIRI (Hyperspectral Infrared Imager), is expected to cover the entire globe once every 19 days. This new source of HNB data will provide continuous spectra leading to spectral signatures of every target (Fig. 8). However, for any given application (such as agricultural cropland studies), this HNB data will also yield a significant number of redundant bands, which once identified can be ignored.

\section{Optimal HNBs and HVIs versus Whole Spectral Analysis: A Discussion}

As shown in this research, the entire spectrum is not required for many applications, due to redundant HNBs. This study achieved three key goals in characterizing eight major world agricultural crop biophysical and biochemical characteristics by:

A. Overcoming the Hughes Phenomenon (or the curse of high dimensionality of hyperspectral data) by utilizing 


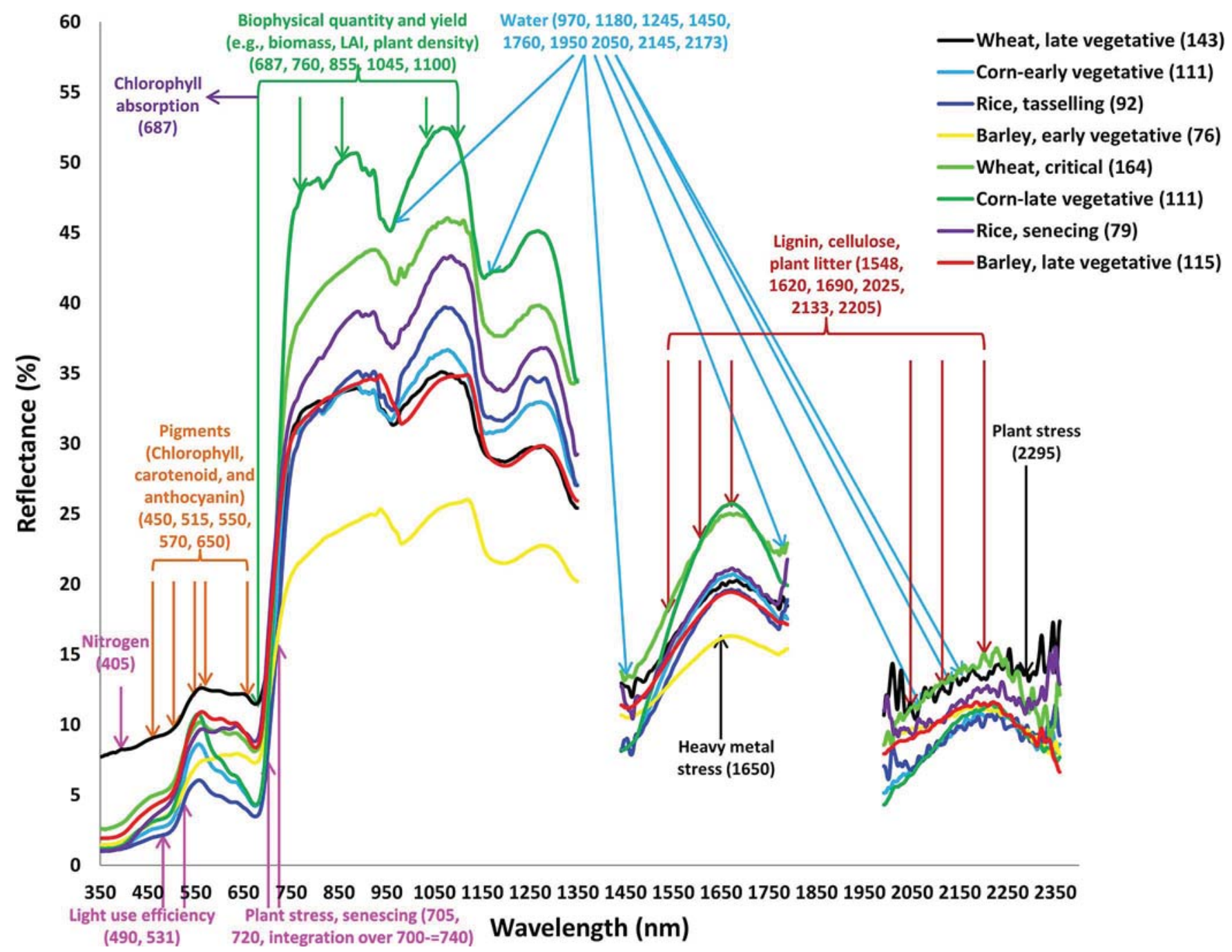

Fig. 8. Optimal hyperspectral narrowbands (HNBs). Current state of knowledge on hyperspectral narrowbands (HNBs) for agricultural and vegetation studies (inferred from [8]). The whole spectral analysis (WSA) using contiguous bands allow for accurate retrieval of plant biophysical and biochemical quantities using methods like continuum removal. In contrast, studies on wide array of biophysical and biochemical variables, species types, crop types have established: (a) optimal HNBs band centers and band widths for vegetation/crop characterization, (b) targeted HVIs for specific modeling, mapping, and classifying vegetation/crop types or species and parameters such as biomass, LAI, plant water, plant stress, nitrogen, lignin, and pigments, and (c) redundant bands, leading to overcoming the Hughes Phenomenon. These studies support hyperspectral data characterization and applications from missions such as Hyperspectral Infrared Imager (HyspIRI) and Advanced Responsive Tactically Effective Military Imaging Spectrometer (ARTEMIS). Note: sample sizes shown within brackets of the figure legend refer to data used in this study.

$\sim 33$ optimal HNBs and ignoring redundant HNBs (e.g., Fig. 5);

B. Targeting specific vegetation biophysical and biochemical variables (e.g., plant moisture, cellulose, lignin, biomass, yield) using the $\sim 33$ most sensitive HVIs. Each of these HVIs are targeted towards a specific study (e.g., plant moisture) as shown in Table IV and Fig. 8; and

C. Improving accuracies in vegetation type or species classification through $\sim 20$ optimal HNBs as illustrated in Figs. 6 and 7.

Nevertheless, the HNBs deemed optimal for biophysical and biochemical characterization of agricultural crops may not be optimal for the study of other applications such as minerals, water, and forests. Therefore, there will always be the need for full spectrum data. Having continuous spectra will be invaluable for: (a) establishing derivative greenness vegetation indices through continual removal that integrates spectra over a range of electromagnetic spectrum, (b) building spectral libraries of ideal or target spectra for spectral matching techniques, and (c) applying spectra for multitude of applications where certain wavebands that are redundant for one application (e.g., biophysical quantification) but invaluable for some other applications (e.g., minerals, water).

\section{E. Relevance of HNBs and HVIs in Crop Classification, Discrimination, and Modeling}

Overall, this research established that $33 \mathrm{HNBs}$ and an equal number of HVIs are the most valuable for studying major world crops (Table IV). Eight of these HNBs are in the far short wave infrared (1945-2230 nm), six in the near short-wave infrared $(1440-1770 \mathrm{~nm})$, three in the near-infrared $(1095-1250 \mathrm{~nm})$, four in the near-infrared $(750-1050 \mathrm{~nm})$, three in the red-edge $(700-745 \mathrm{~nm})$, two in the red $(645-700 \mathrm{~nm})$, four in the green $(510-575 \mathrm{~nm})$, and three in the blue $(400-495 \mathrm{~nm})$. 
TABLE IV

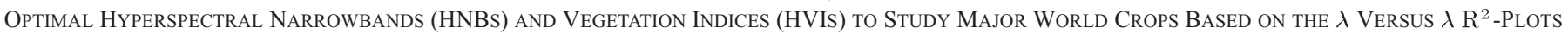
InVolving HNBs or HVIs With Biophysical Parameter Based on This Study and Meta-ANalysis. (Adopted From [8])

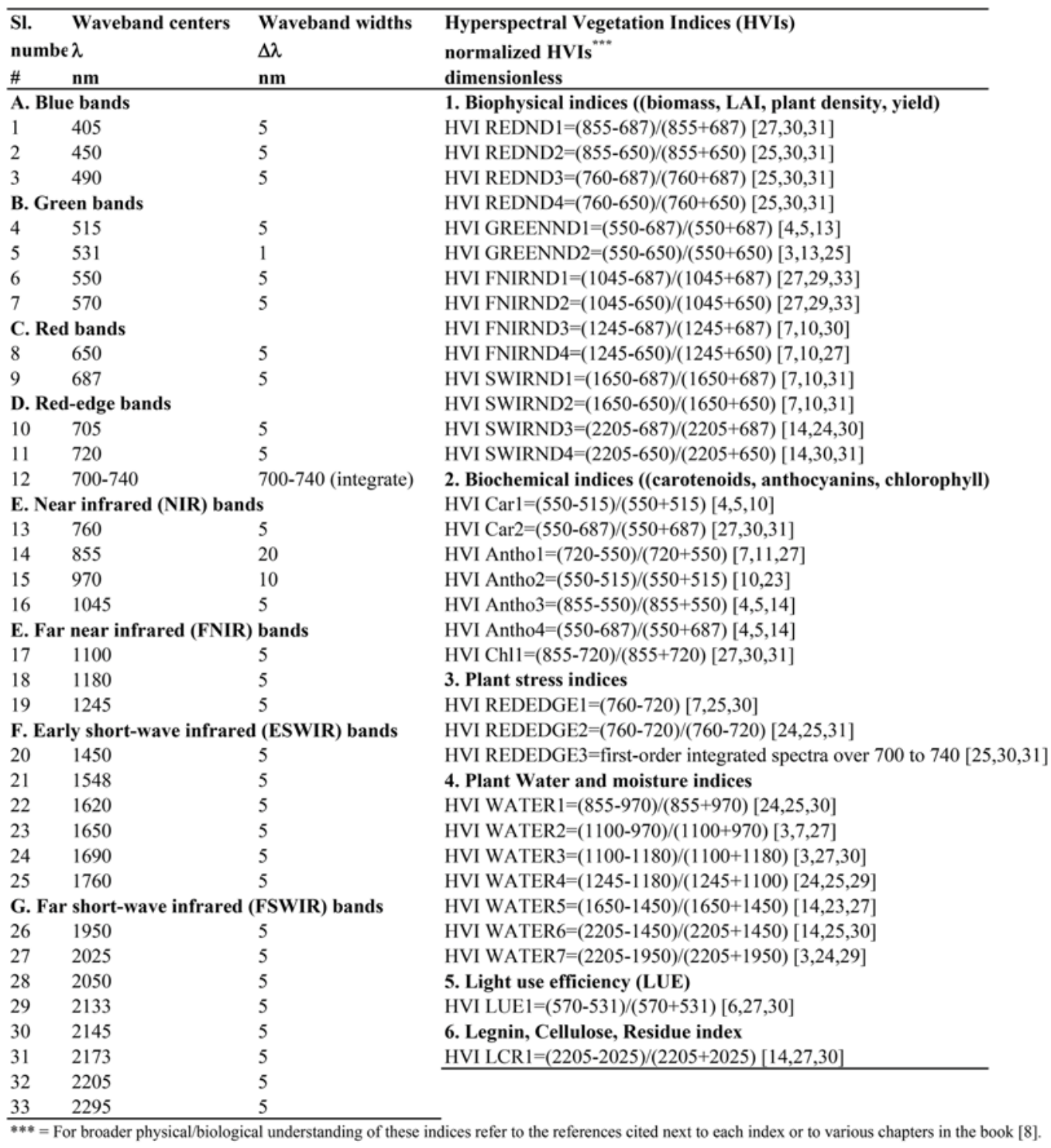

We also found that HNBs used to classify or discriminate agricultural crops (Figs. 6 and 7) became asymptotic between $\sim 20$ to 25 HNBs. Beyond this point, adding additional bands in classification or discrimination of crop types did not statistically provide improvements. The physically meaningful HVIs, computed using the HNBs, are classified into 6 distinct types: (1) biophysical HVIs; (2) biochemical HVIs; (3) plant stress HVIs; (4) plant water and moisture HVIs; (5) light use efficiency HVIs; and (6) lignin, cellulose, and residue HVIs. The physical relevance of these HVIs has also been found by other researchers, as summarized in Table IV.

\section{CONCLUSION}

Several key advances were discussed in this paper. First, optimal hyperspectral narrowbands (HNBs) and hyperspectral vegetation indices (HVIs) were identified for the study of eight major agricultural worldwide crops (wheat, corn, rice, barley, soybeans, pulses, cotton, and alfalfa) that occupy $\sim 70 \%$ of the global cropland areas. There were 33 HNBs (Table IV, Fig. 8) found to be optimal for characterizing, classifying, monitoring, modeling, and mapping these crops.

Second, 33 HVIs were constituted to address six specific crop and vegetation characteristics (Table IV, Fig. 8) based on $\lambda$ versus $\lambda R^{2}$ - plots. Physiological indices such as PRI, NDWI, and ARI established in other studies have their formulations based on criteria other than $\lambda$ versus $\lambda \mathrm{R}^{2}$ - plots. The closest physical/biological rationale for each of the 33 HVIs can be understood from the references provided in Table IV.

Third, approximately $20 \mathrm{HNBs}$ were best able to classify and separate the eight leading world crops. These crops were classified with an overall accuracy of $95 \%$ using $~ 20 \mathrm{HNBs}$, whereas the six non-thermal Landsat ETM+ broadbands provided overall accuracy of $67 \%$, and the nine EO- 1 ALI broadbands provided an overall accuracy of $71 \%$. Therefore, 
the HNBs provide about $25 \%$ greater accuracies when compared with broadbands such as Landsat ETM+ and EO-1 ALI, which should be similar to results forthcoming from Landsat-8.

Fourth, this research further solidified earlier findings [8], [23], [30], [31] that about $90 \%$ of the HNBs are redundant in characterizing, classifying, modeling, and mapping agricultural crops. Identification of these redundant bands will help in overcoming the Hughes Phenomenon. The $\lambda_{1}(350-2500 \mathrm{~nm})$ versus $\lambda_{2}(350-2500 \mathrm{~nm})$ contour plots of $\mathrm{R}^{2}$-values were used to model crop biophysical and biochemical characteristics and determine optimal versus redundant bands. This process, along with the meta-analysis, also helped identify waveband centers $(\lambda)$ and waveband widths $(\Delta \lambda)$ that provide the best relationships, the highest $\mathrm{R}^{2}$-values (Table IV).

Furthermore, the question of whether to use contiguous bands or optimal bands needs careful evaluation. Continuous spectra will be invaluable for: (a) establishing derivative greenness vegetation indices through continual removal that integrates spectra over a range of electromagnetic spectrum, (b) building spectral libraries of ideal or target spectra for spectral matching techniques, and (c) applying spectra for multitude of applications where certain wavebands that are redundant for one application (e.g., biophysical quantification) but invaluable for some other applications (e.g., minerals, water). However, a large number of HNBs will be redundant in characterizing major agricultural crops. Thereby, use of optimal bands will suffice for many purposes.

The results of this study will aid in better understanding of hyperspectral data in agricultural crop characterization, classification, monitoring, modeling, and mapping. This research will also make significant contribution to future hyperspectral missions such as NASA's HyspIRI.

\section{ACKNOWLEDGMENT}

The authors want to thank Dr. Zhuoting Wu for help with Figs. 3 and 8. The four anonymous reviewers and two internal USGS reviewers (Dr. Dennis Dye and Dr. Kristin Byrd) were very insightful in their comments and helped improve the quality of this manuscript. We are grateful to Dr. Elizabeth Middleton, NASA, Guest Editor of this special issue, for the encouragement to put this paper together. Dr. David Landis, Sigma Space Corp. for editing the penultimate version along with Dr. Middleton. The financial support through Land Remote Sensing (LRS) and Geographic Analysis and Monitoring (GAM) Programs of the U.S. Geological Survey are gratefully acknowledged. The authors are thankful to NASA Science Mission Directorate's Earth Science Division for the research grant in response to NASA ROSES HyspIRI solicitation (NNH10ZDA001N-HYSPIRI). The authors are grateful for continued support and encouragement from Susan Benjamin, Director of the USGS Western Geographic Science Center and Edwin Pfeifer, USGS Southwest Geographic Team Chief. Finally, the authors would like to thank USGS John Wesley Powell Center for Analysis and Synthesis for funding the Working group on Global Croplands (WGGC). Our special thanks to Powell Center Directors: Jill Baron and Marty Goldhaber. Inputs from WGGC team members (http://powellcenter.usgs.gov/current_projects.php\#GlobalCroplandMembers) are acknowledged. The WGGC web site (https://powellcenter.usgs.gov/globalcroplandwater/) support provided by Megan Eberhardt Frank, Gail A. Montgomery, Tim Kern and others is deeply appreciated.

\section{REFERENCES}

[1] C. Y. Wu, X. Z. Han, Z. Niu, and J. J. Dong, "An evaluation of EO-1 hyperspectral Hyperion data for chlorophyll content and leaf area index estimation," Int. J. Remote Sens., vol. 31, pp. 1079-1086, 2010.

[2] B. Datt, T. R. McVicar, T. G. Van Niel, D. L. B. Jupp, and J. S Pearlman, "Preprocessing EO-1 Hyperion hyperspectral data to support the application of agricultural indexes," IEEE Trans. Geosci. Remote Sens., vol. 41, pp. 1246-1259, Jun. 2003.

[3] V. Alchanatis and Y. Cohen, "Spectral and spatial methods for hyperspectral image analysis for estimation of biophysical and biochemical properties of agricultural crops," in Hyperspectral Remote Sensing of Vegetation, P. S. Thenkabail, J. G. Lyon, and A. Huete, Eds. Boca Raton, London, New York: CRC Press/Taylor and Francis Group, 2011, ch. 13, pp. 289-305.

[4] A. Gitelson, "Non-destructive estimation of foliar pigment (chlorophylls, carotenoids, and anthocyanins) contents: evaluating a semi-analytical three-band model," in Hyperspectral Remote Sensing of Vegetation, P. S. Thenkabail, J. G. Lyon, and A. Huete, Eds. Boca Raton, London, New York: CRC Press/Taylor and Francis Group, 2011, ch. 6, pp. $141-166$

[5] A. Gitelson, "Remote estimation of crop biophysical characteristics at various scales," in Hyperspectral Remote Sensing of Vegetation, P. S. Thenkabail, J. G. Lyon, and A. Huete, Eds. Boca Raton, London, New York: CRC Press/Taylor and Francis Group, 2011, ch. 15, pp. 329-360.

[6] E. Middleton, K. F. Huemmrich, Y. B. Cheng, and H. A. Margolis, "Spectral bioindicators of Photosynthetic Efficiency and vegetation stress," in Hyperspectral Remote Sensing of Vegetation, P. S. Thenkabail, J. G. Lyon, and A. Huete, Eds. Boca Raton, London, New York: CRC Press/Taylor and Francis Group, 2011, ch. 12, pp. 265-288.

[7] D. A. Roberts, "Hyperspectral vegetation indices," in Hyperspectral Remote Sensing of Vegetation, P. S. Thenkabail, J. G. Lyon, and A. Huete, Eds. Boca Raton, London, New York: CRC Press/Taylor and Francis Group, 2011, ch. 14, pp. 309-328.

[8] P. S. Thenkabail, G. J. Lyon, and A. Huete, "Advances in hyperspectral remote sensing of vegetation and agricultural crops," in Hyperspectral Remote Sensing of Vegetation, P. S. Thenkabail, J. G. Lyon, and A. Huete, Eds. Boca Raton, London, New York: CRC Press/Taylor and Francis Group, 2011, ch. 1, pp. 3-29.

[9] M. L. Clark, "Identification of canopy species in tropical forests using hyperspectral data," in Hyperspectral Remote Sensing of Vegetation, P. S. Thenkabail, J. G. Lyon, and A. Huete, Eds. Boca Raton, London, New York: CRC Press/Taylor and Francis Group, 2011, ch. 18, pp. 423-446.

[10] L. S. Galvão, "Crop type discrimination using hyperspectral data," in Hyperspectral Remote Sensing of Vegetation, P. S. Thenkabail, J. G. Lyon, and A. Huete, Eds. Boca Raton, London, New York: CRC Press/Taylor and Francis Group, 2011, ch. 17, pp. 397-422.

[11] R. Pu, "Detecting and mapping invasive plant species by using hyperspectral data," in Hyperspectral Remote Sensing of Vegetation, P. S Thenkabail, J. G. Lyon, and A. Huete, Eds. Boca Raton, London, New York: CRC Press/Taylor and Francis Group, 2011, ch. 19, pp 447-468.

[12] J. Qi, Y. Inoue, and N. Wiangwang, "Hyperspectral sensor systems and data characteristics in global change studies," in Hyperspectral Remote Sensing of Vegetation, P. S. Thenkabail, J. G. Lyon, and A. Huete, Eds. Boca Raton, London, New York: CRC Press/Taylor and Francis Group, 2011, ch. 3, pp. 69-92.

[13] J. Li, C. Li, D. Xhao, and C. Gang, "Non-destructive estimation of foliar pigment (chlorophylls, carotenoids, and anthocyanins) contents: Evaluating a semianalytical three-band model," in Hyperspectral Remote Sensing of Vegetation, P. S. Thenkabail, J. G. Lyon, and A. Huete, Eds. Boca Raton, London, New York: CRC Press/Taylor and Francis Group, 2011, ch. 6, pp. 141-166. 
[14] T. Slonecker, "Hyperspectral analysis of the effects of heavy metals on vegetation reflectance," in Hyperspectral Remote Sensing of Vegetation, P. S. Thenkabail, J. G. Lyon, and A. Huete, Eds. Boca Raton, London, New York: CRC Press/Taylor and Francis Group, 2011, ch. 23, pp. 561-578.

[15] H. Yao, L. Tang, L. Tian, R. L. Brown, D. Bhatnagar, and T. E. Cleveland, "Using hyperspectral data in precision farming applications," in Hyperspectral Remote Sensing of Vegetation, P. S. Thenkabail, J. G. Lyon, and A. Huete, Eds. Boca Raton, London, New York: CRC Press/Taylor and Francis Group, 2011, ch. 25, pp. 591-610

[16] J. Zwart, "Benchmarking water productivity in agriculture and the scope for improvement: Remote sensing modeling from field to global scale," Ph.D. dissertation, , University of Delft, Delft, The Netherlands, 2010, p. 107.

[17] S. J. Zwart and W. G. M. Bastiaanssen, "Review of measured crop water productivity values for irrigated wheat, rice, cotton and maize," Agricultural Water Management, vol. 69, pp. 115-133, 2004.

[18] S. J. Zwart and W. G. M. Bastiaanssen, "SEBAL for detecting spatial variation of water productivity and scope for improvement in eight irrigated wheat systems," Agricultural Water Management, vol. 89, pp. 287-296, 2007.

[19] W. Bastiaanssen, B. Thoreson, B. Clark, and G. Davids, "Discussion of application of SEBAL model for mapping evapotranspiration and estimating surface energy fluxes in south-central Nebraska," J. Irrig. Drain Eng., vol. 136, p. 282, 2010.

[20] W. G. M. Bastiaanssen, "SEBAL-based sensible and latent heat fluxes in the irrigated Gediz Basin, Turkey," J. Hydrol., vol. 229, pp. 87-100, 2000.

[21] W. G. M. Bastiaanssen, M. Menenti, R. A. Feddes, and A. A. M. Holtslag, "A remote sensing surface energy balance algorithm for land (SEBAL). 1. Formulation,” J. Hydrol., vol. 212-213, pp. 198-212, 1998.

[22] J. G. Wesseling and R. A. Feddes, "Assessing crop water productivity from field to regional scale," Agricultural Water Management, vol. 86, pp. 30-39, 2006

[23] P. S. Thenkabail, G. J. Lyon, and A. Huete, "Hyperspectral remote sensing of vegetation and agricultural crops: Knowledge gain an knowledge gap after 40 years of research," in Hyperspectral Remote Sensing of Vegetation, P. S. Thenkabail, J. G. Lyon, and A. Huete, Eds. Boca Raton, London, New York: CRC Press/Taylor and Francis Group, 2011, ch. 28, pp. 663-668.

[24] S. Ullah, M. Schlerf, A. K. Skidmore, and C. Hecker, "Identifying plant species using mid-wave infrared $(2.5-6 \mu \mathrm{m})$ and thermal infrared (8-14 $\mu \mathrm{m})$ emissivity spectra," Remote Sens. Environ., vol. 118, pp. 95-102, 2012.

[25] R. N. Clark and T. V. V. King, in Proc. 3rd Airborne Imaging Spectrometer Data Analysis Workshop, 1987, pp. 132-137, JPL Publication.

[26] R. N. Clark and T. L. Roush, "Reflectance spectroscopy: Quantitative analysis techniques for remote sensing applications," J. Geophys. Res., vol. 89, pp. 6329-6340, 1984.

[27] G. Vane, in Introduction to the Proc. 2nd Airborne Imaging Spectrometer (AIS) Data Analysis Workshop, 1986, pp. 1-16, JPL Publication.

[28] R. Øystein and D. T. Øivind, "Evaluation of FLAASH atmospheric correction," SAMBA/10/12 Norsk Regnesentral, Norwegian Computing Center, 2012.

[29] J. C.-W. Chan and D. Paelinckx, "Evaluation of random forest and Adaboost tree-based ensemble classification and spectral band selection for ecotope mapping using airborne hyperspectral imagery," Remote Sens. Environ., vol. 112, pp. 2999-3011, 2008.

[30] S. Bajwa and S. S. Kulkarni, "Hyperspectral data mining," in Hyperspectral Remote Sensing of Vegetation, P. S. Thenkabail, J. G. Lyon, and A. Huete, Eds. Boca Raton, London, New York: CRC Press Taylor and Francis Group, 2011, ch. 4, pp. 94-116.

[31] P. S. Thenkabail, R. B. Smith, and E. De Pauw, "Hyperspectral vegetation indices and their relationships with agricultural crop characteristics," Remote Sens. Environ., vol. 71, pp. 158-182, Feb. 2000.

[32] P. S. Thenkabail, M. Hanjra, V. Dheeravath, and M. Gumma, "A holistic view of global croplands and their water use for ensuring global food security in the 21 st century through advanced remote sensing and non-remote sensing approaches," Remote Sens., vol. 2, pp. 211-261, 2010.

[33] P. S. Thenkabail, "Optimal hyperspectral narrowbands for discriminating agricultural crops," Remote Sens. Rev., vol. 20, pp. 257-291, 2001
[34] P. S. Thenkabail, E. A. Enclona, M. S. Ashton, C. Legg, and M. J. De Dieu, "Hyperion, IKONOS, ALI, and ETM+ sensors in the study of African rainforests," Remote Sens. Environ., vol. 90, pp. 23-43, 2004.

[35] P. S. Thenkabail, E. A. Enclona, M. S. Ashton, and B. Van Der Meer, "Accuracy assessments of hyperspectral waveband performance for vegetation analysis applications," Remote Sens. Environ., vol. 91, pp. 354-376, 2004.

[36] G. Agrawal, "Comparision of QUAC and FLAASH atmospheric correction modules on EO-1 Hyperion data of Sanchi," Int. J. Advanced Engineering Sciences and Technologies, vol. 4, pp. 178-186, 2011.

[37] M. Y. Jollineau and P. J. Howarth, "Mapping an inland wetland complex using hyperspectral imagery," Int. J. Remote Sens., vol. 29, pp. $3609-3631,2008$

[38] C. C. Aggarwal and P. S. Yu, "Outlier detection for highdimensional data," in SIGMOD'01: Proc. 2001 ACM SIGMOD Int. Conf. Management of Data, New York, NY, USA, 2001, pp. 37-46.

[39] P. S. Chavez and P. S. , "An improved dark-object subtraction technique for atmospheric correction of multispectral data," Remote Sens. Environ., vol. 24, pp. 459-479, 1986.

[40] P. S. Chavez, "Image-based atmospheric corrections - Revisited and improved," Photogramm. Eng. Remote Sens., vol. 62, no. 9, pp. $1025-1036,1996$

[41] R. Houborg, M. C. Anderson, J. M. Norman, T. Wilson, and T. Meyers, "Intercomparison of a 'bottom-up' and 'top-down' modeling paradigm for estimating carbon and energy fluxes over a variety of vegetative regimes across the U.S.," Agricultural and Forest Meteorology, vol. 149, pp. 1875-1895, 2009.

[42] "SAS/STAT user's guide and software release, version 9.2," SAS Inst.. Cary, NC, USA, 2009

[43] R. G. Congalton and K. Green, Assessing the Accuracy of Remotely Sensed Data: Principles and Practices, 2nd ed. Boca Raton: CRC/ Taylor and Francis, 2009, p. 183.

[44] C. Monfreda, N. Ramankutty, and J. A. Foley, "Farming the planet: 2. Geographic distribution of crop areas, yields, physiological types, and net primary production in the year 2000," Global Biogeochem. Cycles, vol. 22, p. GB1022, 2008.

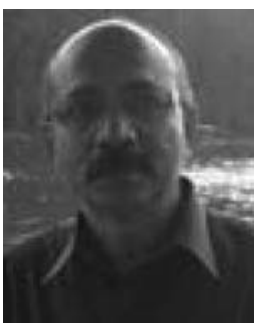

Prasad S. Thenkabail is a Research Geographer 15 with the U.S. Geological Survey (USGS), USA. He has more than 28 years experience as a well-recognized international expert in remote sensing and geographic information systems (RS/GIS) and their application to agriculture, wetlands, natural resource management, water resources, forests, sustainable development, and environmental studies. Recently, as a principal investigator he won a NASA Making Earth System data records for Use in Research Environments (NASA MEaSUREs) grant $(\sim 3.5$ million dollars over 5 years; 2013-2018) for developing a Food Security-support Analysis Data at $30 \mathrm{~m}$ (GFSAD30). His work experience spans over 25 countries in West and Central Africa, Southern Africa, South Asia, Southeast Asia, the Middle East, East Asia, Central Asia, North America, South America, and the Pacific

Dr. Thenkabail has conducted pioneering scientific research work in two major areas: hyperspectral remote sensing of vegetation, and global irrigated and rainfed cropland mapping. His research papers on these topics are widely quoted. He has published two seminal books in these areas of expertise: Hyperspectral Remote Sensing of Vegetation and Remote Sensing of Global Croplands for Food Security (CRC/Taylor and Francis). Currently, he is the global coordinator for Agriculture Societal Beneficial Area (SBA) of the Committee for Earth Observation Systems (CEOS), co-lead of Water for the World Project (IEEE effort), chair of International Society of Photogrammetry and Remote Sensing (ISPRS) Working Group WG VIII/7: "Land Cover and Its Dynamics, Including Agricultural and Urban Land Use" for the period 2013-2016. The USGS and NASA selected him to be on the Landsat Science Team (2007-2011) for a period of five years.

Dr. Thenkabail has received many awards, including: Environmental System Research Institute (ESRI) for "special achievement in GIS" (SAG award) for their Tsunami related work, Second Place Recipients of the 2008 John I. Davidson ASPRS President's Award for practical papers, and 1994 Autometric Award of the American Society of Photogrammetric Engineering and Remote Sensing (ASPRS). He was on scientific advisory board of the Rapideye (a German Satellite Company). He is on the editorial board of Remote Sensing of Environment, ISPRS Journal of Photogrammetry and Remote Sensing, and is the Editor-in-Chief of Remote Sensing Open Access Journal. He is Adjunct Professor in three universities: 1) Department of Space 
Studies, University of North Dakota (UND), 2) Department of Soil, Water, and Environmental Science (SWES), University of Arizona (UoA), and 3) School of Earth Sciences \& Environmental Sustainability, Northern Arizona University. He has a Ph.D. (agricultural engineering; remote sensing) from the Ohio State University, USA, Master's (Hydraulics and Water Resources Engineering), and Bachelor's (Civil Engineering) from India. He has more than 100 publications, mostly peer-reviewed research papers in major international remote sensing journals. His detailed professional profile can be found at: https://profile.usgs.gov/pthenkabail/.

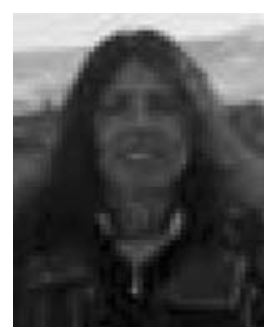

Isabella Mariotto received the Bachelor and Master degrees in natural sciences from the University of Padova, Italy, in 1995, and the M.S. and the Ph.D. in ecology with emphasis on GIS and remote sensing at New Mexico State University, Las Cruces, NM, USA, in 2010.

She is a remote sensing and GIS research Assistant Professor with the Environmental Science program in the Geological Sciences Department, University of Texas, El Paso, TX, USA. She also worked as a research scientist with the U.S. Geological Survey and the University of Arizona on a NASA grant project on hyperspectral remote sensing of water use and water productivity of key world crops in central Asia She is interested in exploring the interactions between vegetation biophysical processes and land-surface parameters through multispectral and hyperspectral remote sensing and GIS spatial modeling.

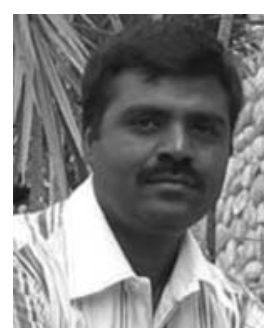

Murali Krishna Gumma is currently a Remote Sensing Scientist at the International Rice Research Institute (IRRI), Philippines. Before that he was a project scientist at the International Water Management Institute (IWMI). He has more than 14 years' experience working as a well-recognized international expert in remote sensing and geographic information systems (RS/GIS). He has vast experience working in more than 16 countries of Africa, South Asia, Southeast Asia, and Central Asia. His broad research interests relate to land use and land cover characterization, Monitoring cropland areas and identify drought and submergence areas. He was one of the core team members in a variety of Remote Sensing and GIS application projects at IWMI, with significant contributions to the Global Irrigated Area Mapping (GIAM) at various resolutions, harmonization of IWMI's spatial data gateway (IWMIDSP), and Wetlands Mapping using RS/GIS techniques. Currently, he is working on five projects with IRRI: 1) Seasonally updated information on rice agro-ecologies using innovative remote-sensing and mapping systems, 2) Characterization of abiotic and biotic stresses in major rice growing areas, 3) Developing the spatial model for selecting the best sites for Rice cultivation in the inland valley agro ecosystems using multi-resolution remote sensing and GIS spatial modeling, and 4) estimation of areas of adoption of sub1 varieties (for submergence) and of short duration varieties (for drought avoidance) and 5) Impact assessment. $\mathrm{He}$ is the author of 32 peer-reviewed scientific papers, 1 academic book, 16 conference papers and presentations, 2 research reports and 4 book chapters. In 2009, Dr. Gumma got second best Ph.D. thesis award from the Jawaharlal Nehru Technological University, Hyderabad, India. In 2008, he was one of the key co-authors of a path breaking paper (Spectral Matching Techniques used in mapping global irrigated areas) which was the Second Place Recipients of the 2008 John I. Davidson ASPRS President's Award for practical papers (for their paper on). In June 2007, he was a key member of the team recognized by the Environmental System Research Institute (ESRI) for "special achievement in GIS" (SAG award) for their Tsunami related work (tsdc.iwmi.org) and for their innovative spatial data portals (http://waterdata.iwmi.org/dtViewCommon.php; earlier http://www.iwmidsp.org).

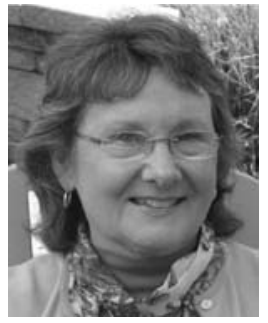

Elizabeth M. Middleton received the B.S. degree in zoology from the University of Maryland in 1967, the M.S. degree in ecology from the University of Maryland in 1976, and the Ph.D. degree in botany from the University of Maryland in 1993.

She is a Senior Scientist with the Laboratory for Biospheric Sciences (Code 618) at NASA/GSFC, Greenbelt, MD. She is currently the Mission Scientist for the Earth Exploring One (EO-1) satellite and the GSFC lead for the NASA HyspIRI satellite concept development.

Dr. Middleton recently received in 2011 a Career Achievement Award from the Hydrospheric and Biospheric Sciences Laboratory at GSFC. She also received NASA Group Achievement Awards in 1983, 1994, 1995 and 2003, respectively, in addition to numerous Performance Awards. She has previously served, and is currently serving, as the Outside Observer on the Mission Advisory Group (2007-2009, 2011+) for a European Space Agency's Phase A satellite mission concept - the FLuorescence Explorer (FLEX). In addition, she was a member of NASA/GSFC Carbon Cycle Science Working Group (2000-2007) and the NASA representative to the US Federal Geographic Data Committee's Vegetation Subcommittee for many years. Dr. Middleton leads a research team that studies vegetation spectral bio-indicators of plant stress and photosynthetic function, including plant fluorescence. She is Associate Editor of Journal of Applied Remote Sensing.

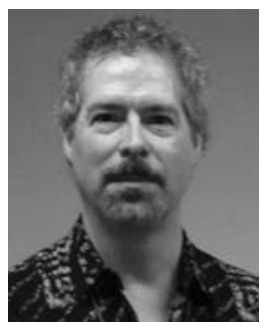

David R. Landis received the B.S. degree in computer programming from Elizabethtown College, Elizabethtown, PA, USA.

$\mathrm{He}$ is a Senior Programmer with the Biospheric Sciences Laboratory (Code 618) at NASA/GSFC, Greenbelt, MD. He is currently working on the Earth Exploring One (EO-1) satellite. He has over 25 years of experience as a contract staff programmer-analyst at GSFC. He has experience working for MODIS, Landsat, and EO-1. His information technology experience is extensive, having worked on data systems and data publication tasks for five large climatology projects (FIFE, BOREAS, BOREAS Follow-on, SAFARI 2000, ISLSCP-2). He has considerable programming skill and Web designer experience. He also has significant science background, and has worked with scientists in many disciplines.

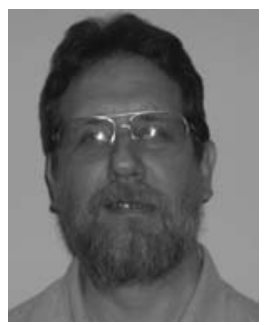

Karl Fred Huemmrich received the B.S. degree in physics from Carnegie-Mellon University, Pittsburgh, PA, USA, and the Ph.D. in geography from the University of Maryland, College Park, MD, USA.

He is currently a Research Associate Professor in the Joint Center for Earth Systems Technology at the University of Maryland Baltimore County. He has developed and used models of light interactions with vegetation, and has studied the use of remotely sensed data to collect information on biophysical variables and land cover type using both computer models and field measurements. His research has involved fieldwork in a variety of habitats including working on operations and data analysis for the Boreal Ecosystem and Atmosphere Study (BOREAS) and the First International Satellite Land Surface Climatology Project Field Experiment (FIFE). 